\title{
Role of Computed Tomography in the Pre operative Diagnosis of Clear Cell Renal Carcinoma
}

Kaleem Ur Rahman, Ameet Jesrani* and Mubarak Ali

Department of Radiology, Sindh Institute of Urology and Transplantation, Karachi, Pakistan

*Corresponding author: Dr. Ameet Jesrani, Department of Radiology, Sindh Institute of Urology and Transplantation, Karachi, Pakistan, Tel: 03342629397, 03002727967; E-mail: ameet.jesrani@yahoo.com

Received date: October 30, 2017; Accepted date: November 28, 2017; Published date: December 04, 2017

Copyright: @2017 Ur Rahman K, et al. This is an open-access article distributed under the terms of the Creative Commons Attribution License, which permits unrestricted use, distribution, and reproduction in any medium, provided the original author and source are credited.

\begin{abstract}
Background: Renal cell carcinoma (RCC) accounts for $3 \%$ of all human malignant tumors. The behavior of RCC apparently depends on its subtype. CT scan can provide detailed information about the tumor itself and regarding its precise extension. The pre-histological diagnosis of clear cell renal carcinoma could be made with more precision on the basis of CT scan features and would ultimately play a major role in the prognosis and management of the disease.
\end{abstract}

Objective: To determine the diagnostic accuracy of computed tomography in the diagnosis of clear cell renal carcinoma taking histopathological findings as gold standard.

Methods: Total 100 patients had renal mass were included. All patients underwent contrast enhanced CT scan. On the basis of CT scan features a pre-surgical diagnosis of histological subtype of RCC, clear cell renal carcinoma was made. The patients were followed by nephrectomy. The diagnostic accuracy of CT scan was determined.

Results: The male to female ratio was $3.2: 1.0$. Out of total study subjects $85.0 \%$ patients turned out to be renal cell carcinomas and among these $40(47 \%)$ were right sided and $45(53 \%)$ were left sided. The mean size of tumor was $12.75 \mathrm{~cm}$. The sensitivity, specificity, and diagnostic accuracy of CT scan were $89.0 \%, 72.7 \%$, and $86.0 \%$ respectively.

Conclusion: The CT scan was helpful in diagnosing clear cell renal carcinoma. The most valuable parameter was the degree of enhancement of clear cell renal carcinoma with other parameters playing supplemental role.

Keywords: Diagnostic accuracy; Computed tomography; Clear cell renal carcinoma; Histopathology

\section{Introduction}

Renal cell carcinoma accounts for $3 \%$ of all visceral malignant tumors and seventh most common histological type of cancer in the western world, proving a significant cause of morbidity and mortality $[1,2]$. This is the According to the First International Workshop on Renal Cell Carcinoma held by the World Health Organization, Renal cell carcinoma can be classified into Conventional or Clear cell renal carcinoma (Papillary renal carcinoma, Chromophobe renal carcinoma, Collecting duct renal carcinoma, Medullary renal carcinoma, and Unclassified renal carcinoma). Sarcomatoid degeneration can occur in all subtypes [3]. The behavior of renal cell carcinoma apparently depends on its subtype with some subtypes having comparatively favorable prognosis while others having grave. Therefore, precise prediction of the subtype preoperatively has significant implications in planning appropriate treatment options and estimating the prognosis of patients $[4,5]$.

The five year survival rate is different amongst the various subtypes of renal cell carcinoma, for example, for clear cell it is $55-60 \%$, papillary $80-90 \%$, Chromophobe has the best approximately $90 \%$, collecting duct $5 \%$, while poorest for Medullary carcinoma with an average survival of 15 weeks ,therefore different subtypes of renal cell carcinoma have different prognostic value [6]. Image guided biopsy provides relatively high accuracy (70-90\%) in preoperative characterization of renal mass $[7,8]$. However, it is minimally invasive, involves risk and has limitations.

CT scan has been widely used for the evaluation of renal cell carcinoma because it can provide detailed information about the tumor itself and also regarding its precise extension $[6,9,10]$. The sensitivity and specificity of helical CT scan for diagnosing renal cell carcinoma is $96 \%$ and $95 \%$ respectively [11]. Contrast-enhanced helical CT scan findings like hypervascularity, calcification, pattern of enhancement etc. are variable amongst the subtypes and hence on this basis, it may help in predicting a specific histological subtype $[6,12]$. Amongst all these, the parameter of degree of enhancement taken in Hounsfield units (HU) in the corticomedullary and pyelographic phase has a high sensitivity of $74-84 \%$ and specificity ranging from 91-100\% in differentiating clear cell from nonclear cell renal cell carcinoma [9]. Therefore the pre-histological diagnosis of clear cell renal carcinoma could be made with more precision on the basis of CT features and would ultimately play a major role in the prognosis and management of the disease. 


\section{Materials and Methods}

Total 100 patients of both gender, had renal masses diagnosed on ultrasound with age between 28 to 82 years were included in the study after taking inform concern and approval from institutional ethical committee. The study was conducted from $1^{\text {st }}$ May 2010 to $31^{\text {st }}$ October 2010 at department of radiology, Sindh institute of urology and transplantation, Karachi.

All CT scan were performed using GE advantage scanner (GE electrical medical systems Milwaukee, USA). All the subjects came for $\mathrm{CT}$ scan were called with $4 \mathrm{~h}$ of fasting. Venous access was obtained in the preparation room using an 18-20 G intracath in the antecubital vein or a large vein in the forearm. The subjects were trained to hold their breath with special attention to avoid the diaphragmatic motion. Frontal scout was taken, and then an unenhanced helical CT scan was performed using $7.5 \mathrm{~mm}$ slice thickness, pitch of $120 \mathrm{Kv}, 100-150 \mathrm{~mA}$. $0.8 \mathrm{~s}$ scan time and imaging reconstruction at $2.5 \mathrm{~mm}$ intervals from the diaphragm to mid pelvis during a single breath hold. The delay between the initiation of the injection and the scan was calculated using the "Smart Prep" option (GE medical systems). It ranged from 10 $\mathrm{s}$ to $25 \mathrm{~s}$. Non ionic contrast (Iohexol 100-120 ml $300 \mathrm{mg}$ iodine/ml) was injected at the rate of $4 \mathrm{ml} / \mathrm{s}$ with a power injector and images were taken in the corticomedullary and pyelographic phases along with coronal and sagittal reformations with same parameters. $500-22 \mathrm{~cm}$, $1000 \mathrm{ml}$ of oral contrast in form of water will also be given. CT scan image interpretation was performed on Advantage workstation. A specific solid part of the renal tumor was selected and the CT attenuation value of this part of the tumor was then taken in unenhanced, corticomedullary and pyelographic phases. The degree of enhancement was then calculated by taking the difference between the attenuation values in the unenhanced, corticomedullary and pyelographic phases. Primarily on this and other CT parameters a presurgical diagnosis of clear cell renal carcinoma was then made. Subsequently majority of the patients underwent surgical nephrectomies for their tumors and the histological diagnosis was then compared with the CT diagnosis.

Data were complied and analyzed using SPSS version 21 . Frequency and percentages were obtained for qualitative variables and Mean \pm SD were calculated for quantitative variables. The diagnostic accuracy of CT scan was calculated by as considering histopathology as gold standard.

\section{Results}

Mean age $55.2 \pm 1.8$ years, ranged from $28-82$ years. The male to female ratio was 3.2:1.0. Out of total patients, $85 \%$ turned out to be renal cell carcinomas. Of these 40 (47\%) were right sided and 45 (53\%) were left sided. Amongst these, 72 (84\%) were clear cell carcinoma, 9 (11\%) were papillary cell carcinoma, 4 (5\%) were Chromophobe cell carcinoma. No collecting duct, Medullary or unclassified renal carcinoma was found. The rest of 15 (15\%) renal masses which were diagnosed as RCC came out to be squamous cell carcinoma.

The size of tumor diameter ranged from $2.9-22.6 \mathrm{~cm}$ with mean tumor diameter of $12.75 \mathrm{~cm}$. The tumor spread pattern of renal cell carcinoma were confined $44 \%$ to the kidney, $26 \%$ showed perinephric infiltration, $13 \%$ showed venous invasion, and $17 \%$ presented with lymphadenopathy.

Calcification was more frequently seen in papillary and Chromophobe renal carcinomas then in clear cell variant. Amongst all CT features the most important parameter was the degree of enhancement of renal cell carcinoma (Table 1).

\begin{tabular}{|l|l|l|l|l|l|}
\hline & Unenhanced & $\begin{array}{l}\text { Cortico Medullary } \\
\text { Phase }\end{array}$ & Excretory Phase & $\begin{array}{l}\text { Degree of enhancement } \\
\text { in CM Phase }\end{array}$ & $\begin{array}{l}\text { Degree of enhancement in } \\
\text { Excretory Phase }\end{array}$ \\
\hline Clear Cell RCC & $26-40$ & $89-243$ & $63-100$ & $63-217$ & $37-74$ \\
\hline Papillary RCC & $32-38$ & $53-70$ & $42-69$ & $21-38$ & $10-37$ \\
\hline Chromophobe RCC & $28-48$ & $36-59$ & $51-56$ & $8-31$ & $23-28$ \\
\hline
\end{tabular}

Table 1: Attenuation values and degree of enhancement in HU of different Histological types of RCC.

The attenuation value of clear cell carcinoma on unenhanced CT ranged from 26-40 $\mathrm{HU}$ with mean of $33 \mathrm{HU}$. The attenuation values of clear carcinomas in corticomedullary phase ranged from 89-243 HU with mean attenuation value of $166 \mathrm{HU}$. The attenuation value of clear cell carcinoma in excretory phase ranged from 63-100 HU with mean of $81.5 \mathrm{HU}$. The degree of enhancement of clear cell carcinoma in the corticomedullary phase ranged from 63-217 HU with mean of $140 \mathrm{HU}$. The degree enhancement clear cell carcinoma in the excretory phase ranged from 37-74 HU with mean of 55.5 HU (Figure 1).
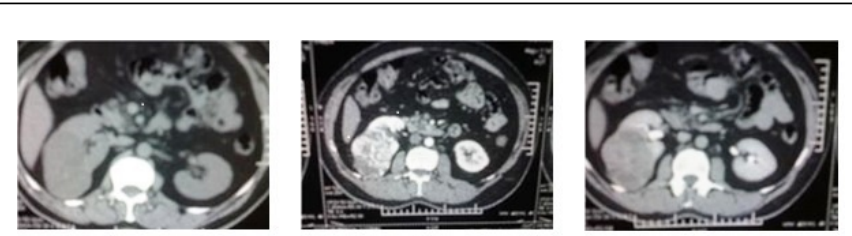

Figure 1: Clear cell carcinoma in corticomedullary and excretory phases.

The attenuation value of Chromophobe cell carcinoma on unenhanced CT was ranged from 32-38 HU with mean $35 \mathrm{HU}$. The attenuation values of Chromophobe cell carcinomas in corticomedullary phase ranged from 53-70 $\mathrm{HU}$ with mean attenuation value of $61.5 \mathrm{HU}$. The attenuation value of Chromophobe cell carcinoma in excretory phase ranged from 42-69 HU with mean 55.5 HU. The degree of enhancement of clear cell carcinoma in the 
corticomedullary phase ranged from 21-38 HU with mean of $29.5 \mathrm{HU}$. The degree enhancement of Chromophobe cell carcinoma in the excretory phase ranged from 10-37 $\mathrm{HU}$ with mean of $23.5 \mathrm{HU}$ (Figure 2).
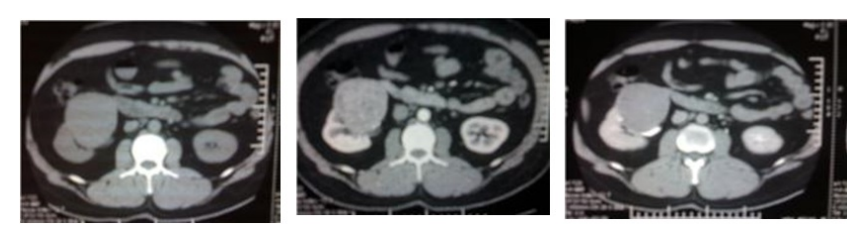

Figure 2: Chromophobe cell carcinoma in corticomedullary and excretory phases.

The attenuation value of papillary cell carcinoma on unenhanced CT was ranged from 28-48 HU with mean $38 \mathrm{HU}$. The attenuation values of papillary cell carcinomas in corticomedullary phase ranged from 36-59 HU with mean attenuation value of $47.5 \mathrm{HU}$. The attenuation value of papillary cell carcinoma in excretory phase ranged from 51-56 HU with mean 53.5 HU. The degree of enhancement of papillary cell carcinoma in the corticomedullary phase ranged from 8-31 HU with mean of $19.5 \mathrm{HU}$. The degree enhancement of papillary cell carcinoma in the excretory phase ranged from 23-28 HU with mean of $25.5 \mathrm{HU}$ (Figure 3).
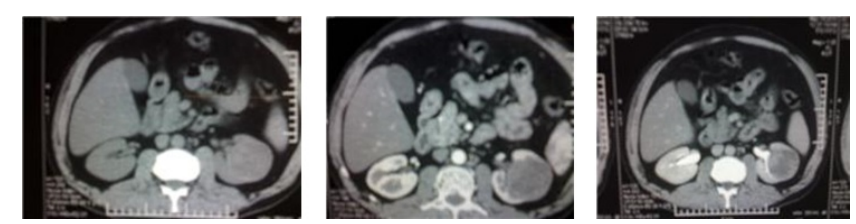

Figure 3: Papillary cell carcinoma in corticomedullary and excretory phases.

The calculated CT scan sensitivity, specificity, PPV, NPV, and diagnostic accuracy were $89.0 \%, 72.7 \%, 92.10 \%, 67.0 \%$ and $86.0 \%$ in diagnosing clear cell renal carcinoma taking histopathology as gold standard.

\section{Discussion}

The classification of renal cell carcinoma is based mainly on the histological subtypes of the tumor [1]. Each subtype is associated with a different prognosis and tumor behavior [4]. The 5 year survival rate is different amongst the various subtype of RCC, for example for clear cell it is $55-60 \%$, papillary $80-90 \%$, Chromophobe has the best approximately $90 \%$, therefore different subtype of RCC have different prognostic value [13].

Precise preoperative identification of subtype of renal cell carcinoma may influence the degree of preoperative evaluation, for example metastasis survey like chest $\mathrm{x}$-ray, CT scan chest and bone scanning may be avoided in a subtype that tends not metastasizes and has good prognosis and vice versa for those which have bed prognosis.

Radical nephrectomy has been indicated as a standard treatment in surgically treatable renal cell carcinoma and similarly and unnecessary wide resection may be avoided in patients with a subtype that is unlikely to recur or metastasizes. Radiation and Chemotherapy are not usually given for the treatment of renal cell carcinoma because research shows that this type of cancer does not respond well to either therapy. However, radiation therapy may be given to people who are not candidates for surgery, or used to help alleviate pain when the cancer has spread beyond the kidneys.

Targeted therapies are designed to attack or interfere with specific genes or cells that have been shown to help with the growth of certain cancers. Drugs such as Afinitor, Sutent, Torisel, and Votrient are treatments used for advanced renal cell carcinoma, meaning the cancer has spread beyond the kidney and likely hasn't responded to other traditional treatments.

In this study, we sought to determine whether multiphasic CT can help in preoperative differentiation of various types of renal cell carcinoma. Various CT parameters like size of tumor, calcification, post contrast enhancement, tumor spread and lymphadenopathy were studies. The CT findings were compared with postsurgical histopathological diagnosis which showed that out of 100 renal tumors 85 were renal cell carcinoma (RCC). Among those 85 renal cell carcinomas, there were 72 clear cell RCC, 9 papillary RCC and 4 Chromophobe RCC. The degree of enhancement was the most useful CT parameter in differentiating between subtypes of RCC.

Various CT parameters like size of tumor, pattern and degree enhancement, calcification and tumor extend that were helpful in differentiation of subtypes of RCC were studied. Amongst all these CT features the degree of enhancement was the most useful parameter in differentiating clear cell versus non-clear cell RCC. Clear cell renal carcinoma showed stronger enhancement than other subtypes of renal cell carcinomas in both the corticomedullary and excretory phases. The tumors that enhanced more than approximately $87 \mathrm{HU}$ in the corticomedullary phase and $64 \mathrm{HU}$ in the excretory phase were most likely to be clear cell renal carcinoma with a CT scan sensitivity and specificity of $89 \%$ and $72.7 \%$ respectively.

The results of this study are like other international studies [14-21]. The study conducted by Bird et al. [15] and Young et al. [16] also proved that RCC and Oncocytoma can be differentiated on the basis of degree on enhancement at multidetector CT. However, Zhange et al. [19] Wildberger et al. [20] and Davidson et al. [21] were unable to differentiate RCC from Oncocytoma. This was because Young et al and Bird et al has relatively larger cohort of these tumor and used four phase protocol rather than three phase protocol. In our study, no Oncocytoma was found on imaging and postoperative histopathology. The remaining 15 tumor in our study were proved to be squamous cell carcinoma.

This study has limitations like small cohort and carried out in single center. The renal masses were evaluated with standard three phase protocol. Also, we did not account for dose of contrast medium and injection rate. The strength of this study is that imaging findings were compared with histopathological diagnosis, which is the gold standard. However, our findings should be validated in larger trial in which lesions are imaged with four phase protocol.

Clear cell RCC has poorer prognosis and great likelihood of metastasis than other subtypes of RCC. In our study, overall diagnostic accuracy of CT scan was $86.0 \%$ in diagnosing clear cell renal carcinoma which is of utmost importance and depending on clinical situation; it may be supplemented or not by confirmatory image guided biopsy. It is particularly useful in clinical decision making. 
Citation: Ur Rahman K, Jesrani A, Ali M (2017) Role of Computed Tomography in the Pre operatve Diagnosis of Clear Cell Renal Carcinoma. J Carcinog Mutagen 8: 309. doi:10.4172/2157-2518.1000309

Page 4 of 4

\section{Conclusion}

In conclusion, the computed tomography is helpful in diagnosing clear cell RCC and differentiating it from non-clear cell subtypes of RCC. The most valuable parameter of CT scan was the degree of enhancement of clear cell renal carcinoma with other parameters playing supplemental role.

\section{References}

1. Jemal A, Sieqel R, Ward E, Hao Y, Xu J, et al. (2008) Cancer statistics, 2008. CA. Cancer J Clin 58: 71-96.

2. Ljunberg B, Campbell SC, Cho HY (2011) The epidemiology of renal cell carcinoma. Eur Urol 60: 615-621.

3. Srinivasa RP, Peter AH, Jay RC, Vamsi RN, John RS, et al. (2006) Common and Uncommon Histologic Subtypes of Renal Cell Carcinoma. Radiograph 26: 1795-1806.

4. Cheville JC, Lohse CM, Zincke H, Weaver AL, Blute M (2003) Comparisons of outcome and prognostic features among histologic subtypes of renal cell carcinoma. Am J Surg Pathol 27: 612-624.

5. Decastro GJ, Mc Kiernan JM (2008) Epidemiology, clinical staging and presentation of renal cell carcinoma. Urol Clin North Am 35: 581-592.

6. Bajwa RPS, Sandhu P, Aulakh BS, Sandhu JS, Sagggar K, et al. (2007) Helical CT Evaluation of Renal Mass lesions. J Indian Acad Med 8: 262-264.

7. Dechet CB, Zincke H, Sebo TJ (2003) Prospective analysis of computerized tomography and needle biopsy with permanent sectioning to determine the nature of solid renal masses in adults. J Urol 169: 71-74.

8. Silverman SG, Gan YU, Mortele KJ (2006) Renal masses in adult patients: the role of percutaneous biopsy. Radiology 240: 6-22.

9. Jeong KK, Tae KK, Han JA, Chung SK, Kyu RK, et al. (2002) Differentiation of Subtypes of Renal Cell Carcinoma on Helical CT Scan. Am J Radfiol 178: 1499-1506.
10. Arshad M, Shahzad SS, Rehan B (2008) Presentation and evaluation of renal masses. Pak Armed Forces Med J 58: 31-35.

11. Takebayashi S, Hidai H, Chiba T, Takagi H, Koike S, et al. (1999) Using Helical CT to evaluate renal cell carcinoma in patients undergoing hemodialysis: value of early enhanced images. J Radiol 162: 1555.

12. Sheir K, Azab M (2005) Differentiating of ranal cell carcinoma subtypes of multislice computerized tomography. J Urol 174: 451-455.

13. Jia HW (2009) Imaging Findings of Common and Uncommon Renal Cell Carcinomas. J Taiwan Urol Assoc 20: 10-14.

14. Kim JK, Kim TK, Ahn HJ, Kim CS, Kim KR, et al. (2002) Differentiation of subtypes of renal cell carcinoma on helical CT scans. AJR 178: 1499-1506.

15. Ruppert Kohlmayr AJ, Uggowitzer M, Meissnitzer T, Ruppert G (2004) Differentiation of renal clear cell carcinoma and renal papillary carcinoma using quantitative CT enhancement parameters. AJR 183: 1387-1391.

16. Jinzaki M, Tanimoto A, Mukai M (2000) Double phase helical CT of small renal parenchymal neoplasms: correlation with pathological findings and tumor angiogenesis. J Comput Assist Tomogr 24: 835-842.

17. Bird VG, Kanagarajah P, Morillo G (2011) Differentiation of oncytoma and renal cell carcinoma in small renal masses $(<4 \mathrm{~cm})$ : the role of four phase computerized tomography. World J Urol 29: 787-792.

18. Young JR, Morgalis D, Sauk S (2013) Clear cell renal cell carcinoma: discrimination from other renal cell carcinoma subtypes and oncocytoma at multiphasic multidetector CT. Radiology 267: 444-453.

19. Zhange J, Lefkowitz RA, Ishil NM (2007) Solid renal cortical tumors: differentiation with CT. Radiology 174: 494-504.

20. Wildberger JE, Adam G, Boeckmann W (1997) Computed tomography characterization of renal cell tumors in correlation with histopathology. Invest Radiol 32: 596-601.

21. Davidson AJ, Hayes WS, Hartman DS, McCarthy WG, Davis CJ Jr (1993) Renal oncocytoma and carcinoma failure of differentiation with CT. Radiology 186: 693-696. 